\title{
A Putative RNA-Binding Protein Positively Regulates Salicylic Acid-Mediated Immunity in Arabidopsis
}

\author{
Yiping Qi, ${ }^{1}$ Kenichi Tsuda, ${ }^{1}$ Anna Joe,,${ }^{2,3}$ Masanao Sato, ${ }^{1}$ Le V. Nguyen, ${ }^{1}$ Jane Glazebrook, ${ }^{1}$ \\ James R. Alfano, ${ }^{2}$ Jerry D. Cohen, ${ }^{4}$ and Fumiaki Katagiri ${ }^{1}$ \\ ${ }^{1}$ Department of Plant Biology, Microbial and Plant Genomics Institute, University of Minnesota, 1500 Gortner Avenue, \\ St. Paul 55108, U.S.A.; ${ }^{2}$ Center for Plant Science Innovation and Department of Plant Pathology and ${ }^{3}$ Center for Plant \\ Science Innovation and School of Biological Sciences, University of Nebraska, Lincoln 68588, U.S.A.; and ${ }^{4}$ Department \\ of Horticultural Science, University of Minnesota, 1970 Folwell Avenue, St. Paul, 55108, U.S.A.
}

Submitted 9 May 2010. Accepted 2 July 2010.

\begin{abstract}
RNA-binding proteins (RBP) can control gene expression at both transcriptional and post-transcriptional levels. Plants respond to pathogen infection with rapid reprogramming of gene expression. However, little is known about how plant RBP function in plant immunity. Here, we describe the involvement of an RBP, Arabidopsis thaliana RNA-binding protein-defense related 1 (AtRBP-DR1; At4g03110), in resistance to the pathogen Pseudomonas syringae pv. tomato DC3000. AtRBP-DR1 loss-of-function mutants showed enhanced susceptibility to $P$. syringae pv. tomato $\mathrm{DC3000}$. Overexpression of $A t R B P-D R I$ led to enhanced resistance to $P$. syringae pv. tomato DC3000 strains and dwarfism. The hypersensitive response triggered by $P$. syringae pv. tomato DC3000 avrRpt 2 was compromised in the Atrbp-dr1 mutant and enhanced in the $A t R B P-D R 1$ overexpression line at early time points. $A t R B P-D R 1$ overexpression lines showed higher mRNA levels of $S I D 2$ and $P R 1$, which are salicylic acid (SA) inducible, as well as spontaneous cell death in mature leaves. Consistent with these observations, the SA level was low in the Atrbp-dr1 mutant but high in the overexpression line. The SA-related phenotype in the overexpression line was fully dependent on SID2. Thus, AtRBPDR1 is a positive regulator of SA-mediated immunity, possibly acting on SA signaling-related genes at a post-transcriptional level.
\end{abstract}

Plants have evolved inducible immunity against a variety of pathogens. One mode of inducible immunity is triggered by microbe- or pathogen-associated molecular patterns (MAMPs or PAMPs), which are recognized by pattern recognition receptors (PRR) (Ausubel 2005; Jones and Dangl 2006). For example, a conserved 22-amino-acid fragment (flg22) of bacterial flagellin can be recognized by the FLS2 PRR to activate immune responses (Gomez-Gomez and Boller 2000; Zipfel et al. 2004). The disease resistance triggered in this manner is called PAMP-triggered immunity (PTI) (Jones and Dangl 2006). Pathogens well adapted to particular plant hosts deliver

Corresponding author: Fumiaki Katagiri; Telephone: +1.612.624.5195; Fax: +1.612.624.6264; E-mail: katagiri@umn.edu

Current address for M. Sato: Okazaki Institute for Integrative Bioscience, National Institute for Basic Biology, National Institutes of Natural Sciences, Higashiyama, Myodaiji, Okazaki 444-8787, Japan.

* The $e$-Xtra logo stands for "electronic extra" and indicates that nine supplementary figures and one supplementary table are published online. effectors that can interfere with PTI. Plants can activate another mode of immunity triggered upon perception of pathogen effector proteins by plant disease resistance $(\mathrm{R})$ proteins. For example, the Arabidopsis $\mathrm{R}$ protein RPS2 recognizes the bacterial effector AvrRpt2 to trigger immunity (Bent et al. 1994; Mindrinos et al. 1994). The immunity triggered in this way is called effector-triggered immunity (ETI) (Jones and Dangl 2006).

Both PTI and ETI use the salicylic acid (SA) pathway to defend against biotrophic and hemibiotrophic pathogens, such as Pseudomonas syringae (Shah 2003; Glazebrook 2005; Tsuda et al. 2008, 2009). Many genes involved in SA signaling have been identified. For example, the SID2 gene encodes the SA biosynthesis enzyme isochorismate synthase (Wildermuth et al. 2001) and the NPR1 gene encodes an important positive regulator of SA responses (Cao et al. 1997; Mou et al. 2003). Activation of the SA pathway leads to high expression of many genes, including pathogenesis-related $1(P R l)$, which is thus a good marker gene for activation of this pathway. However, successful biotrophic and hemibiotrophic pathogens have evolved mechanisms to antagonize SA-mediated immunity. For example, some $P$. syringae strains secrete the phytotoxin coronatine, which is a structural mimic of the jasmonic acid (JA)-isoleucine conjugate, the active form of the plant hormone JA (Bender et al. 1999; Thines et al. 2007). The pathogens seem to use coronatine to suppress the SA pathway (Zhao et al. 2003; Uppalapati et al. 2005; Thilmony et al. 2006) based on the inhibitory effect of the JA pathway on the SA pathway (Schenk et al. 2000; Glazebrook et al. 2003). Also, effectors produced by $P$. syringae, such as HopM1, AvrE, and HopI1, have been shown to suppress SA signaling in plants (DebRoy et al. 2004; Jelenska et al. 2007).

Gene expression is controlled at both transcriptional and post-transcriptional levels. RNA-binding proteins (RBP) are involved in multiple post-transcriptional processes. After protein-coding genes are transcribed into pre-mRNA by RNA polymerase II, processing and modification steps, such as splicing, are required to produce functional mRNA that is ready for export from the nucleus to the cytoplasm (Lorkovic 2009). The cytoplasmic mRNAs can be translated or degraded (Lorkovic 2009). RBP can regulate all of these processes. For example, approximately $30 \%$ of Arabidopsis genes are thought to be alternatively spliced, and RBP, such as serine/arginine-rich (SR) proteins, are involved in selection of splice sites and recruitment of the splicing machinery to selected splice sites (Reddy 2007). Plant RBP are characterized by the presence of RNA-binding domains, such as the RNA recognition motif 
(RRM) or the K-homology (KH) domain (Lorkovic 2009). The Arabidopsis genome contains more than 200 putative RBP genes, and some of them have been shown to be involved in abiotic stress responses and flowering (Lorkovic and Barta 2002; Kim et al. 2005; Kim et al. 2007, 2008; Lorkovic 2009).

A large percentage of genes in the plant genome respond transcriptionally to pathogen attack (Tao et al. 2003; Thilmony et al. 2006). In addition to reprogramming of transcription, post-transcriptional regulation also plays a role in the plant immune response. For example, alternatively spliced transcript forms of both $N$ and RPS4 R genes are required for their full function (Dinesh-Kumar and Baker 2000; Zhang and Gassmann 2003). A glycine-rich RBP family member, GRP7, was shown to be involved in the plant immune response ( $\mathrm{Fu}$ et al. 2007). GRP7 is required for defense against $P$. syringae pathogens and is targeted by the effector HopU1 for mono-ADP-ribosylation (Fu et al. 2007). In addition, GRP7 is involved in many other biological processes, such as seed germination (Kim et al. 2008), cold response (Kim et al. 2008), stomata opening and closing (Kim et al. 2008), circadian rhythm (Staiger et al. 2003; Schoning et al. 2007), and flowering (Streitner et al. 2008). Discovery of RNA-binding proteins involved in plant immunity will contribute to our understanding of post-transcriptional regulation in plant responses to pathogens.

Here, we report the functional characterization of a putative RBP that affects plant immunity. It contains three RRM motifs and was named AtRBP-defense related 1 (AtRBP-DR1). Lossof-function mutants of AtRBP-DRl were more susceptible to $P$. syringae pv. tomato DC3000 compared with wild-type plants, whereas AtRBP-DRl overexpression lines were more resistant. Also, the Atrbp-drl mutant accumulated less SA. Overexpression of $A t R B P-D R 1$ constitutively activated the SA pathway in a SID2-dependent manner. Thus, AtRBP-DR1 affects SA-mediated immunity to hemibiotrophic pathogens.

\section{RESULTS AND DISCUSSION}

\section{$A t R B P-D R 1$ mutants are compromised in resistance to $P$. syringae pv. tomato $\mathrm{DC} 3000$.}

In our previous work, we used co-immunoprecipitation followed by mass spectrometry to identify proteins making complexes with RPS2 using relatively stringent criteria (Qi and Katagiri 2009). We applied relaxed criteria to identify more putative RPS2-complex component proteins for further study, including AtRBP-DR1 (At4g03110) (Supplementary Fig. 1) (Qi and Katagiri, 2009).

AtRBP-DR1 contains three RRM, with two close to the N terminus and one close to the $\mathrm{C}$ terminus (Fig. 1A). The presence of more than one RRM (as in AtRBP-DR1) is thought to enhance RNA binding affinity and specificity (Clery et al. 2008). Two A. thaliana T-DNA lines with insertions in AtRBPDR1 (SALK_041205 and SALK_141510) were obtained from the Arabidopsis Biological Resource Center. According to the Arabidopsis Information Resource (Swarbreck et al. 2008), SALK_041205 has a T-DNA insertion in the second exon, while SALK_141510 has a T-DNA insertion in the second intron of $A t R B P-D R l$ (Fig. 1B). The AtRBP-DRl transcript was not detected in either mutant using reverse-transcription polymerase chain reaction (RT-PCR) but it was in wild-type plants (Fig. 1B), indicating that both T-DNA insertions abolished mRNA accumulation. Thus, both SALK_041205 and SALK 14150 are null alleles of AtRBP-DR1. They were named Atrbp$d r l-1$ and Atrbp-drl-2, respectively.

The Atrbp-drl mutants were used to test for a role of AtRBP$D R 1$ in disease resistance. Growth of $P$. syringae pv. tomato DC3000 strains carrying an empty vector or constructs encoding AvrRpm1 or AvrRpt 2 in the Atrbp-drl mutants was com- pared with that in wild-type plants. Inclusion of strains expressing AvrRpm 1 and AvrRpt 2 allowed us to determine the extent to which ETI was affected in Atrbp-drl mutants. Both Atrbpdrl-1 and Atrbp-drl-2 mutants allowed significantly more growth of $P$. syringae pv. tomato DC3000 than wild-type plants, with a difference of approximately $0.3 \log _{10}$ units (Fig. 1C). Similar bacterial growth differences were observed with P. syringae pv. tomato DC3000 avrRpml (Fig. 1D) and avrRpt2 (Fig. 1E), indicating that the mutations reduce the basal resistance level but do not have a significant effect on ETI. The small effect of the mutations on bacterial growth may be due to existence of a gene that is partially functionally redundant. The closest homolog of AtRBP-DR1, At1g03457, shares $67 \%$ amino acid identity. Because both mutant alleles showed essentially the same phenotype, the observed phenotype is almost certainly caused by the mutations in AtRBP-DRl and not by incidental mutations in other genes.

To further confirm that the observed phenotype was caused by the mutations, complementation of the mutant phenotype with the wild-type transgene was attempted. The genomic sequence of $A t R B P-D R 1$ (without the stop codon) containing approximately $1.5 \mathrm{~kb}$ upstream (as the promoter) was cloned into the Gateway binary vector pEG303 (Earley et al. 2006) to fuse the Myc epitope tag to the C-terminus of AtRBP-DR1. The resulting construct was used to transform Atrbp- $d r 1-1$ mutant plants. T1 plants were first selected for BASTA resistance and then screened for AtRBP-DRI::Myc expression with immunoblots using anti-Myc antibody. Transgenic plants with detectable protein levels were retained. Among their progeny, T2 plants of two independent transgenic lines, AtRBP$D R 1:: M y c-1$ and AtRBP-DRI::Myc-8, were used to test for complementation of the $P$. syringae pv. tomato DC3000 avrRpt 2 growth phenotype. Both transgenic lines were able to complement the mutant phenotype (Supplementary Fig. 2). Moreover, AtRBP-DR1::Myc-8 T2 plants were more resistant than wild-type plants. The results suggest not only that the AtRBP-DR $1: \because M y c$ transgene was functional and complemented the mutant phenotype but also that overexpression of AtRBP$D R 1$ may enhance disease resistance to $P$. syringae pv. tomato DC3000.

\section{$A t R B P-D R 1$ overexpression enhances resistance to $P$. syringae pv. tomato DC3000 and leads to dwarfism.}

To confirm that the chosen complementation lines had enhanced resistance against $P$. syringae pv. tomato DC3000 strains, T3 plants homozygous for the transgenes were obtained from lines AtRBP-DR $1:: M y c-1$ and AtRBP-DR1::Myc-8. The bacterial growth assay with $P$. syringae pv. tomato DC3000 strains was performed to compare these two transgenic lines with wild-type plants. Indeed, significant reduction of bacterial growth in both transgenic lines compared with wild-type plants was observed (Fig. 2A and B). Furthermore, both AtRBP-DR $1:: M y c-1$ and AtRBP-DR $1: \because M y c-8$ plants were smaller than wild-type plants and the Atrbp-drl-1 mutant (Fig. $2 \mathrm{C})$. Both the enhanced resistance and the morphological phenotype may be due to the AtRBP-DR $1:: M y c$ expression levels. To test this hypothesis, constructs for expressing $M y c:: A t R B P$ $D R 1$ and AtRBP-DRI::YFP::HA under the control of the constitutive Cauliflower mosaic virus (CaMV) $35 S$ promoter were made and used to transform Atrbp-drl-1 mutants. T1 transgenic plants of various sizes ranging from very small to normal were observed. For each construct, one dwarf plant and one plant of relatively normal size were chosen to obtain T3 plants for further study (Fig. 2C). Immunoblot analysis with both anti-Myc and anti-hemagglutinin (HA) antibodies confirmed that the severity of dwarfism was correlated with protein levels of AtRBP-DR1 (Fig. 2D). Thus, we conclude that overexpression 
of $A t R B P-D R 1$ enhances disease resistance to $P$. syringae pv. tomato DC3000 strains and leads to dwarfism.

$A t R B P-D R 1$ overexpression activates the SA pathway.

It is known that SA signaling plays a major role in defense against biotrophic or hemibiotrophic pathogens such as $P$. syringae pv. tomato DC3000 (Shah 2003; Glazebrook 2005). Also, dwarf plant phenotypes can result from elevated SA levels, as found in Arabidopsis cpr (Clarke et al. 2000) and dnd (Clough et al. 2000; Jurkowski et al. 2004) mutants. It is conceivable that overexpression of AtRBP-DRl activates the SA pathway and, thus, leads to dwarf plants. To examine this possibility, we conducted quantitative (q)RT-PCR to monitor the mRNA levels of AtRBP-DRI and two SA marker genes, SID2 and $P R 1$, in the eight lines shown in Figure 2C. All four transgenic lines expressing AtRBP-DRI from the $35 S$ promoter showed significantly higher AtRBP-DRI mRNA levels than wild-type plants (Fig. 3A). The mRNA levels of SID2 and $P R-1$ were high in most AtRBP-DRl transgenic lines (Fig. $3 \mathrm{~B}$ and C). The mRNA level of $P R-1$ was significantly higher in both
AtRBP-DR1::Myc-1 and AtRBP-DR1::Myc-8 lines than in wildtype plants (Fig. 3C), which is consistent with the observed enhanced resistance to $P$. syringae pv. tomato DC3000 in these two lines. Importantly, the expression levels of AtRBP-DRl, $S I D 2$, and $P R 1$ in all eight lines were positively correlated (Fig. 3D). Collectively, these results suggest that AtRBP-DR1 has a positive effect on SA signaling.

To further test AtRBP-DRI's role in the SA pathway, we measured SA in Atrbp-dr1-1, an AtRBP-DR1::Myc-1 overexpression line, and wild-type plants after treatment with PTIinducers (flg22 and the P. syringae pv. tomato DC3000 hrcC mutant) or $P$. syringae pv. tomato DC3000 avrRpt2. P. syringae pv. tomato DC3000 hrcC does not have a functional type III secretion system to deliver effector proteins into plant cells (Deng et al. 1998) and, thus, can only trigger PTI. In mocktreated plants, AtRBP-DR1::Myc-1 had a higher level of SA while the mutant had a lower level compared with the wild type (Fig. 3E). Flg22, P. syringae pv. tomato DC3000 hrcC, and $P$. syringae pv. tomato DC3000 avrRpt 2 treatments induced a dramatic increase of SA in both the mutant and wild-
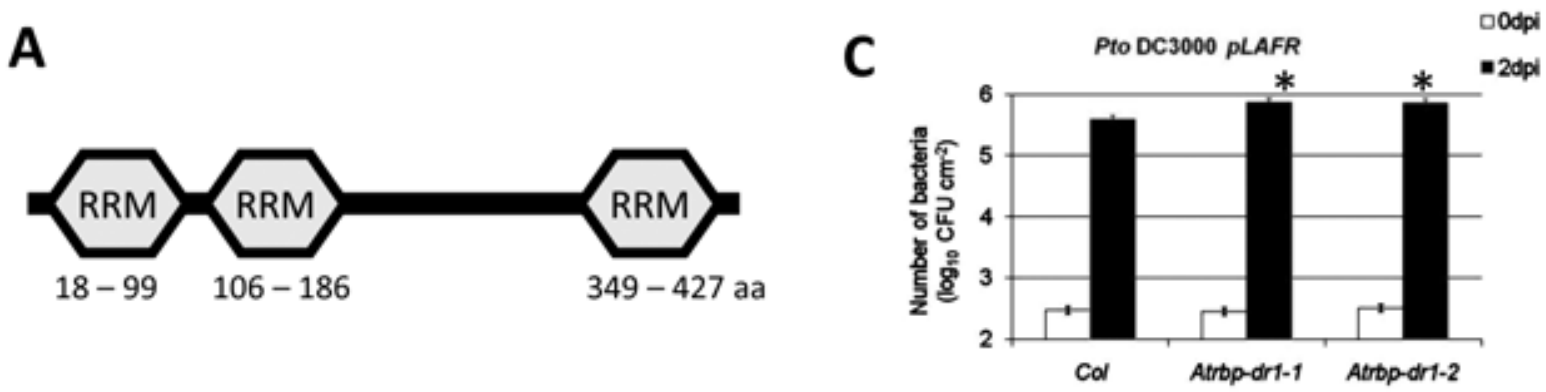

B

D
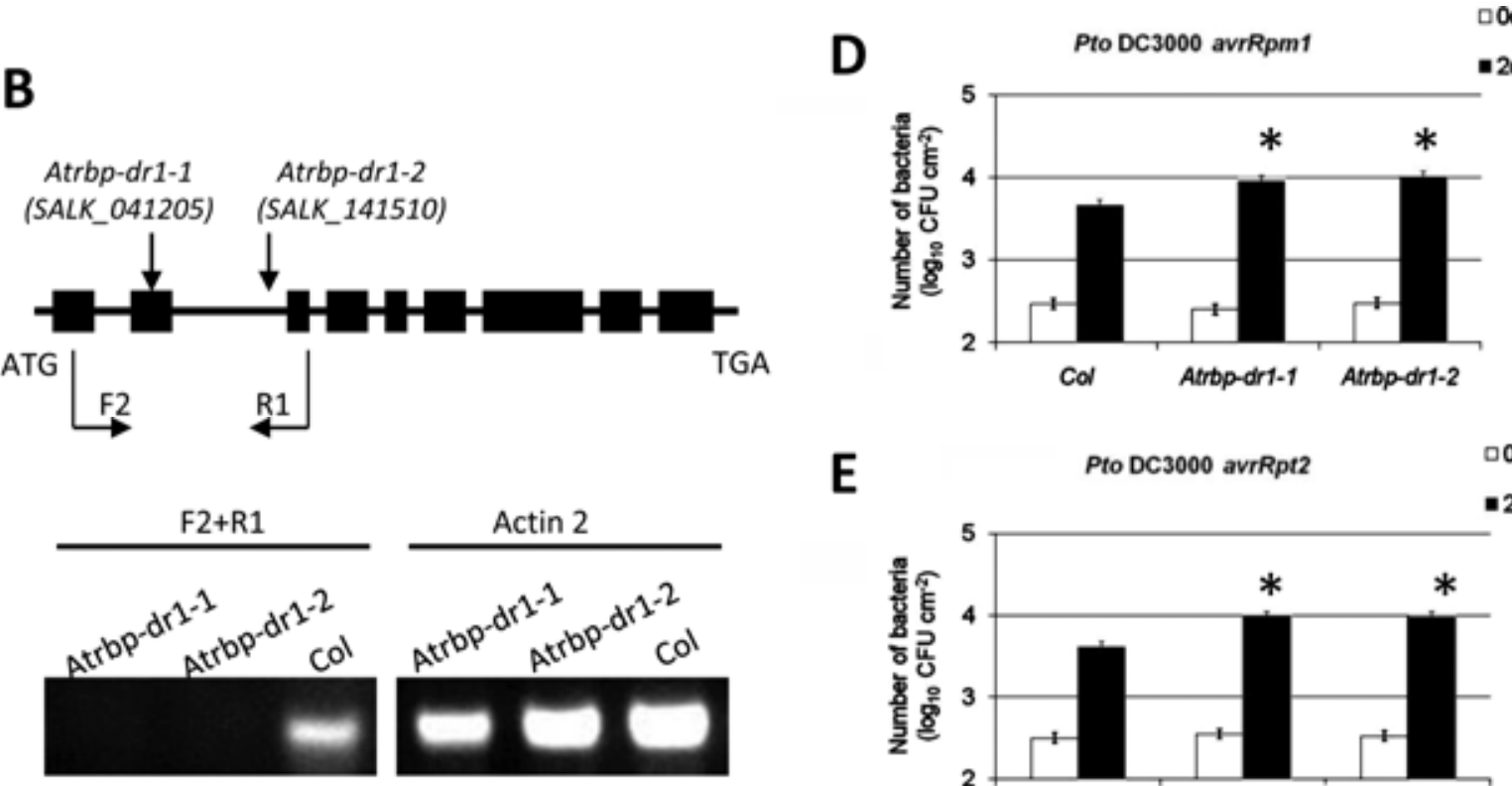

$\mathbf{E}$

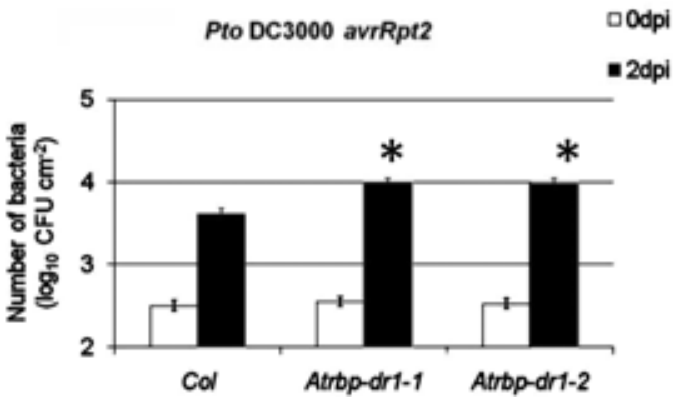

Fig. 1. Resistance to Pseudomonas syringae pv. tomato DC3000 is compromised in AtRBP-DR1 mutants. A, AtRBP-DR1 protein has three RNA recognition motifs (RRM). The RRM were identified by scanning the protein sequence using ScanProsite and their relative positions in the protein are depicted. B, TDNA insertion mutants of AtRBP-DR1 appear to be null. The upper panel depicts a schematic representation of AtRBP-DR1 (At4g03110), with exons shown as black boxes. The T-DNA insertion sites are indicated by arrows. The positions of a pair of primers (F2 and R1), with which reverse-transcription polymerase chain reaction (RT-PCR) was performed to detect AtRBP-DRI transcript, are also shown. The lower panels show the RT-PCR results. The left panel shows detection of AtRBP-DR1 transcript in the two AtRBP-DR1 mutants and the wild type (Col). The right panel shows amplification of Actin2 transcript as a control. C, Atrbp-drl mutants were susceptible to P. syringae pv. tomato DC3000 pLAFR. Leaves of 5-week-old wild-type (Col) and Atrbp-dr1 mutant plants were inoculated with $P$. syringae pv. tomato DC3000 pLAFR at a dose of $2 \times 10^{5} \mathrm{CFU} / \mathrm{ml}$. The bacterial counts were measured at 0 and 2 days postinoculation (dpi). Data were collected in three independent experiments and analyzed using a mixed linear model. Bars represent the mean values with the standard errors. Significant differences between Atrbp-drl mutants and Col are indicated by asterisks for $P<0.005$. D and E, Experiments were conducted and results were analyzed similarly to C, except that the bacterial strains were $\mathbf{D}$, P. syringae pv. tomato DC3000 avrRpm1 and $\mathbf{E}$, P. syringae pv. tomato DC3000 avrRpt2. 
type plants but not in the AtRBP-DRl overexpression line, likely due to the preexisting high SA levels in this line (Fig. $3 \mathrm{E})$. These data indicate that AtRBP-DR1 has a positive effect on SA accumulation.

We also noticed that there was sporadic cell death in old rosette leaves of $A t R B P-D R l$ overexpression lines, such as AtRBP-DR $1:: M y c-1$ and AtRBP-DR $1: \because M y c-8$ (Fig. 3F). The dead cells were evident when the leaves were stained with trypan blue (Fig. 3F). Such a cell death or lesion-mimic phenotype is very likely due to constitutive activation of SA signaling in these plants.

\section{Activation of the SA pathway}

by $A t R B P-D R 1$ overexpression is dependent on SID2.

The SID2 gene encodes an isochorismate synthase, which is required for producing SA during immune responses (Wildermuth et al. 2001). To examine whether the SA in the $A t R B P-D R 1$ overexpression lines is made using this pathway, we introduced a sid2 mutation into the overexpression line AtRBP-DR $1:: M y c-8$. In the F2 generation, AtRBP-DR1::Myc-8 SID2 plants showed dwarfism and spontaneous cell death, indicating accumulation of a higher level of SA (Fig. 4A). However, AtRBP-DR1::Myc-8 sid2 plants were morphologically indistinguishable from wild-type $\mathrm{Col}$ and the sid $2 \mathrm{mu}-$ tant, suggesting that the dwarfism and spontaneous cell death of the AtRBP-DR1 overexpression plants were suppressed by the sid 2 mutation. Thus, the AtRBP-DR1 overexpression phenotype was SID2 dependent. Next, we performed qRT-PCR to examine the level of SID2 dependence by measuring PRI mRNA accumulation in wild-type, sid2, AtRBP-DR1::Myc-8 SID2, and AtRBP-DR1::Myc-8 sid2 plants. The mRNA levels of AtRBP-DR $1: \because M y c$ were comparable in AtRBP-DR $1:: M y c-8$ SID2 and AtRBP-DR1::Myc-8 sid2 plants (Fig. 4B), which indicates that the sid2 mutation does not affect AtRBP$D R 1:: M y c$ expression. As expected, AtRBP-DR1::Myc-8 SID2 plants had a higher level of $P R 1$ expression than the wild type (Fig. 4C). In contrast, AtRBP-DR $1: \because M y c-8$ sid 2 plants showed a PR1 mRNA level which was as low as in sid2 (Fig. 4C). The morphological phenotype and $P R I$ mRNA accumulation data suggest that activation of the SA pathway in AtRBP-DRl overexpression plants is fully dependent on SID2.

\section{$A t R B P-D R 1$ is involved in the hypersensitive response triggered by $P$. syringae pv. tomato DC3000 avrRpt2.}

One characteristic response in ETI is the hypersensitive response (HR), which is evident when plants are challenged with high inocula of bacteria carrying effector genes that induce ETI. Electrolyte leakage can be used to measure the HR quantitatively (Heath 2000). To test whether AtRBP-DR1 is involved in the HR induced by P. syringae pv. tomato DC3000 avrRpt 2 or avrRpml, we conducted an electrolyte leakage assay over a time course with the wild-type, an Atrbp-drl-1 mutant, and an AtRBP-DR1::Myc-1 overexpression line. Atrbp-drl-1 showed slower electrolyte leakage compared with the wild type while AtRBP-DR $1:: M y c-1$ showed faster electrolyte leakage at early time points, when they were challenged with $P$. syringae pv.
A

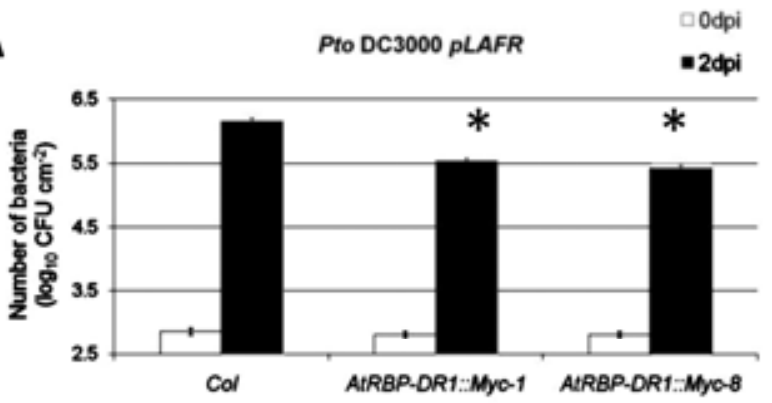

B

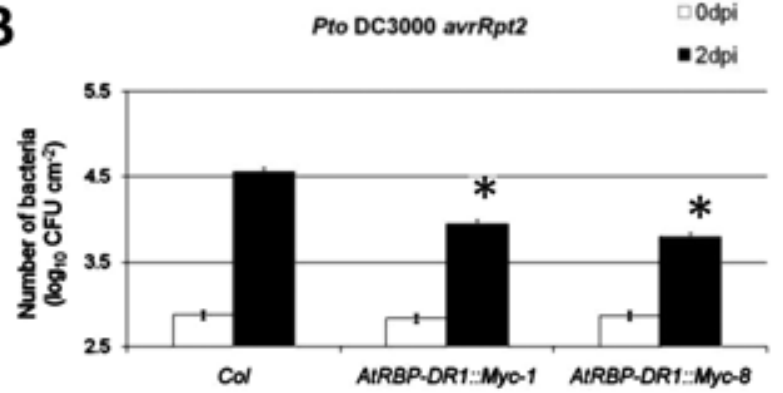

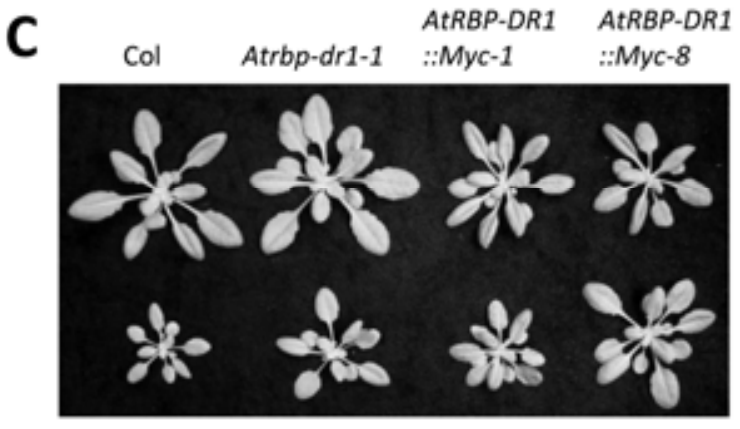

Myc::AtRBP Myc::AtRBP AtRBP-DR1 AtRBP-DR1 $\begin{array}{lll}\text {-DR1-1 } & \text {-DR1-2 } & \text { :YFP::HA-1 }\end{array}$

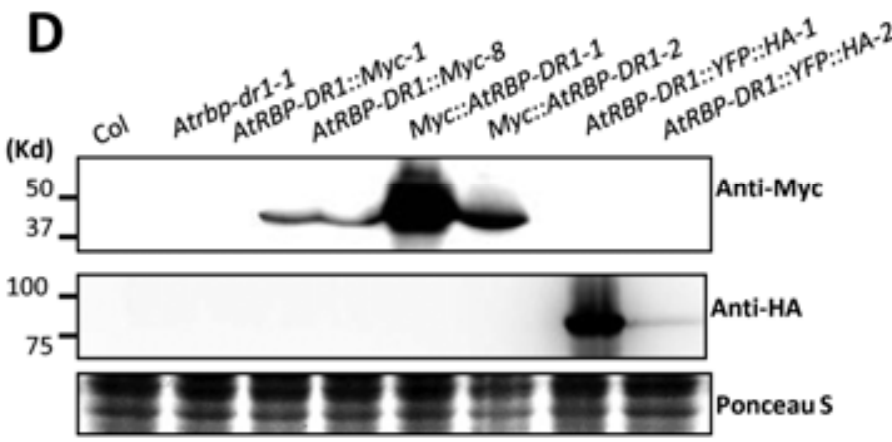

Fig. 2. AtRBP-DR1 overexpression enhances resistance to Pseudomonas syringae pv. tomato DC3000 strains and leads to dwarfism. A, Leaves of 5-weekold Col plants and two AtRBP-DR1 overexpression lines (AtRBP-DR1::Myc-1 and AtRBP-DR1::Myc-8) were inoculated with P. syringae pv. tomato DC3000 pLAFR at a dose of $2 \times 10^{5} \mathrm{CFU} / \mathrm{ml}$. Bacterial counts were measured at 0 and 2 days postinoculation (dpi). Data were collected in two independent experiments and analyzed with a mixed linear model. Bars represent the mean values with the standard errors. Significant differences between the overexpression lines and $\mathrm{Col}$ are indicated by asterisks $\left(P<10^{-15}\right)$. B, Similar experiments were conducted and the results were analyzed as in A, except that the bacterial strain was $P$. syringae pv. tomato DC3000 avrRpt2. C, Morphology of 4-week-old transgenic and control plants. The photograph shows representative plants of Col, Atrbp-dr1-1, and six homozygous transgenic plants expressing epitope tagged AtRBP-DR1 in the Atrbp-dr1-1 mutant background. D, Higher accumulation of AtRBP-DR1 protein correlates with dwarfism among the transgenic plants. The upper and middle panels show immunoblot results using anti-Myc and anti-HA monoclonal antibodies, respectively. The lower panel shows Ponceau S staining of a part of the polyvinylpolypyrrolidone membrane as a loading control. This experiment was done twice with similar results. 
A

B

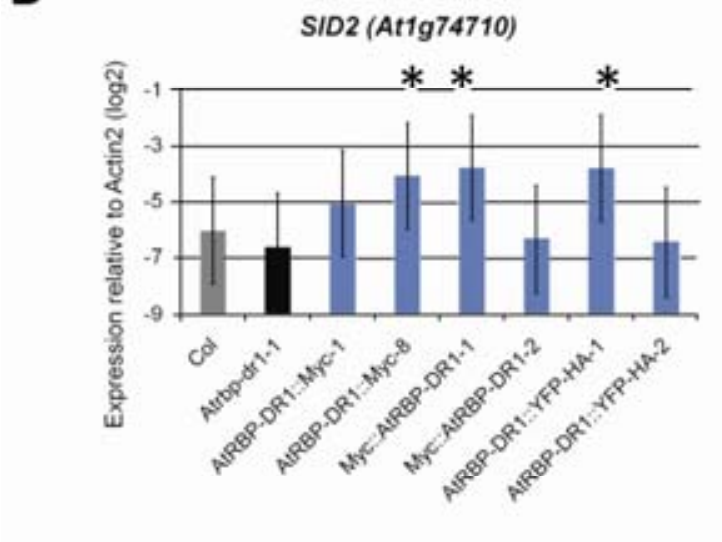

C

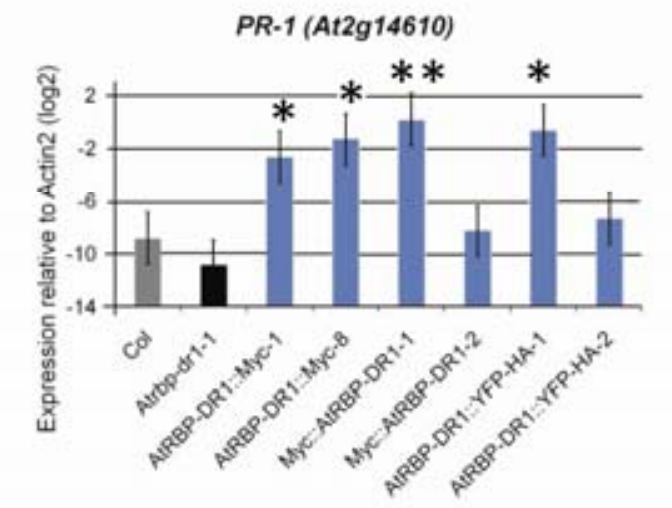

AtRBP.DR1

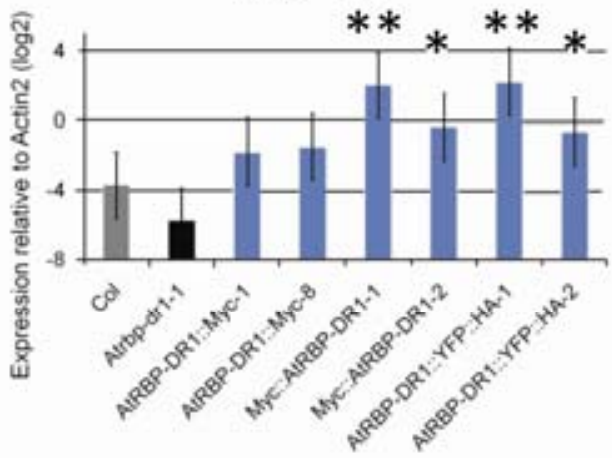

B

C
D

\begin{tabular}{|c|c|c|c|}
\hline $\begin{array}{c}\text { Correlation coefficient } \\
\text { ( } \mathrm{p} \text {-value) }\end{array}$ & AtRBP-DR1 & SID2 & PR1 \\
\hline AtRBP-DR1 & & & \\
\hline & 0.57 & & \\
SID2 & $(0.013)$ & & \\
\hline & 0.63 & 0.85 & \\
PR1 & $(0.006)$ & $(2.48 \mathrm{E}-05)$ & \\
\hline
\end{tabular}

E

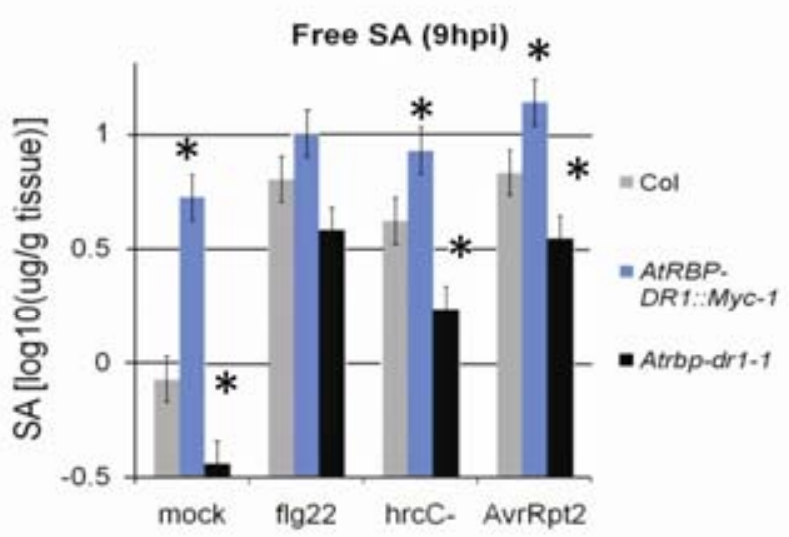

$\mathbf{F}$

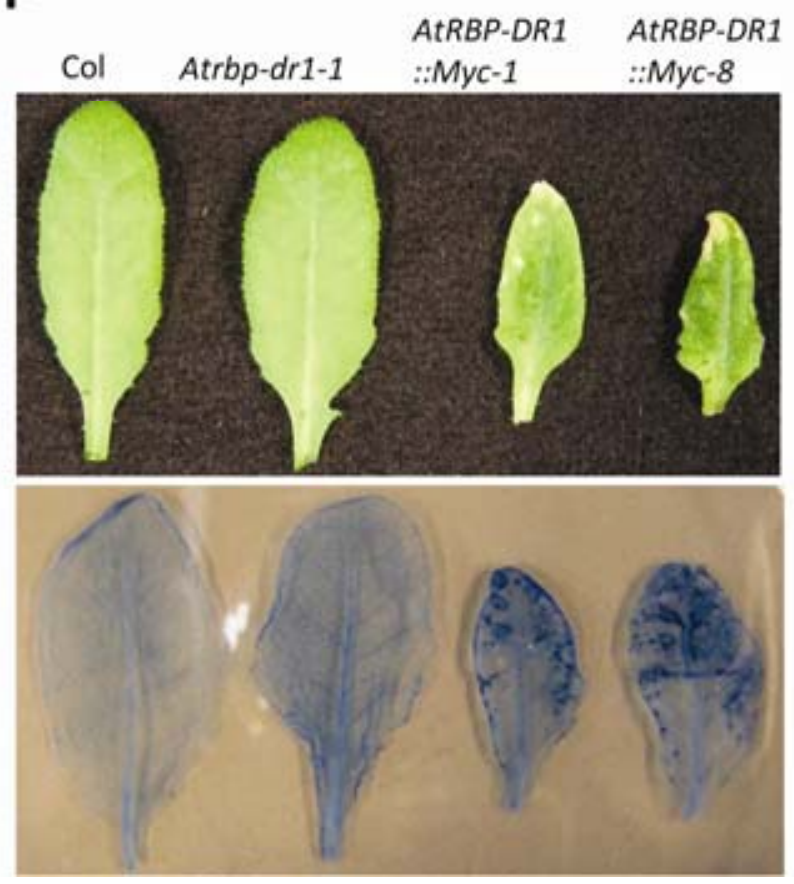

Fig. 3. AtRBP-DR1 overexpression upregulates the salicylic acid (SA) pathway. mRNA levels of the A, AtRBP-DR1; B, SID2 (At1g74710); and C, PR-1 (At2g14610) genes in Col, Atrbp-dr1-1, and six AtRBP-DR1 overexpression lines in the Atrbp-dr1-1 background, determined by quantitative reverse-transcription polymerase chain reaction. The vertical axis represents the $\log _{2}$-transformed $\mathrm{mRNA}$ level relative to Actin2. Data were collected in two independent experiments and analyzed by a mixed linear model. Bars represent the mean values with the standard errors. A and $\mathbf{C}$, Overexpression lines showing significantly higher expression levels than Col were indicated for $P<0.05\left(^{*}\right)$ or $<0.005(* *)$. B, Overexpression lines showing significantly higher expression levels than Atrbp-dr1-1 were indicated for $P<0.1$. D, The AtRBP-DR1, SID2, and $P R-1$ mRNA levels are well correlated across the plant lines. The pairwise Pearson correlation coefficients of the mRNA levels and their associated $P$ values are shown. E, SA level is lower in the mutant and higher in the overexpression lines. Mock (water), $1 \mu \mathrm{M}$ flg22, Pseudomonas syringae pv. tomato DC3000 hrcC $\left(1 \times 10^{8} \mathrm{CFU} / \mathrm{ml}\right)$, or P. syringae pv. tomato DC3000 avrRpt2 $(2 \times$ $10^{7} \mathrm{CFU} / \mathrm{ml}$ ) were infiltrated into 5-week-old Col (gray bars), AtRBP-DR1::Myc-1 (blue bars), or Atrbp-drl-1 (black bars) leaves. The free SA levels at $9 \mathrm{~h}$ postinoculation (hpi) are shown on a $\log _{10}$ scale. Bars represent means and standard errors of two biological replicates calculated by a mixed linear model. Statistically significantly higher or lower SA levels in AtRBP-DR1::Myc-1 or Atrbp-dr1-1 plants compared with Col are indicated (*, $P<0.05)$. F, Photograph of representative 6-week-old rosette leaves of Col, Atrbp-dr1-1, AtRBP-DR1::Myc-1, and AtRBP-DR1::Myc-8 (upper panel) and a photograph of leaves of the same genotypes after trypan blue staining (lower panel). 
tomato DC3000 avrRpt2 (Fig. 5A; Supplementary Figs. 3 and 4). However, no differences were observed among Col, Atrbpdr1-1, and AtRBP-DR1::Myc-1 plants challenged with $P$. syringae pv. tomato DC3000 avrRpml (Fig. 5B). These data

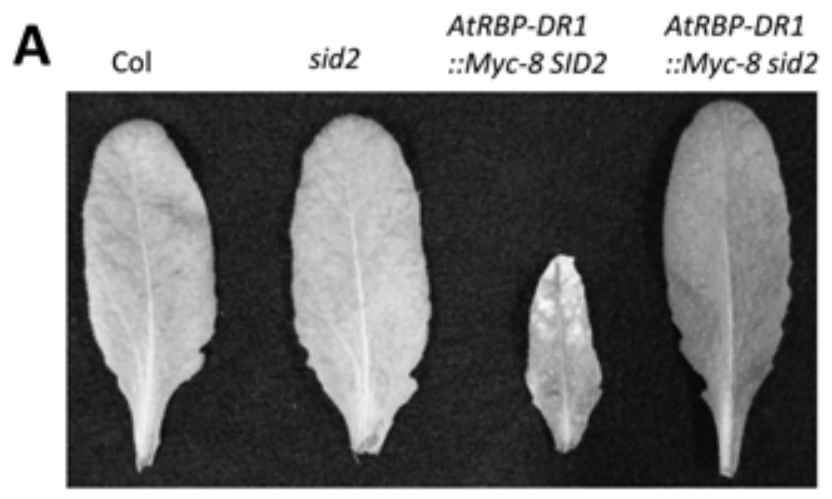

B

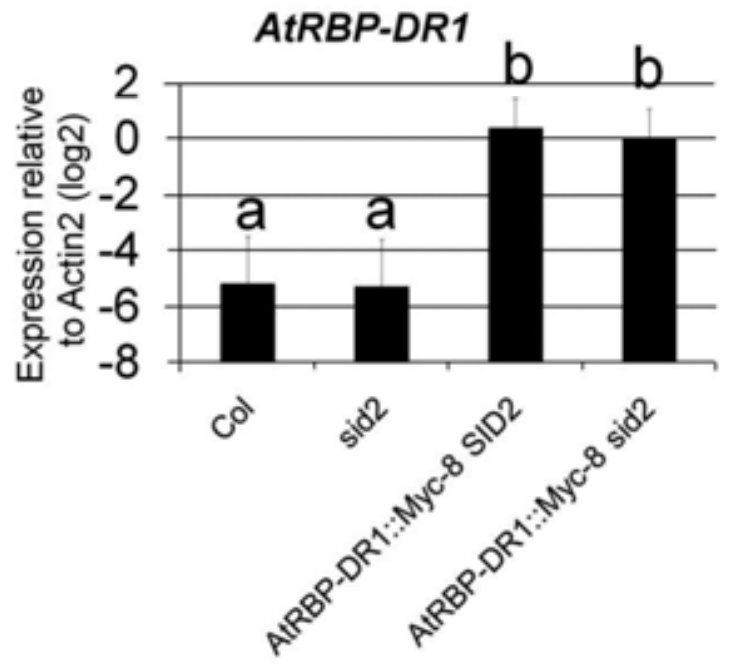

C

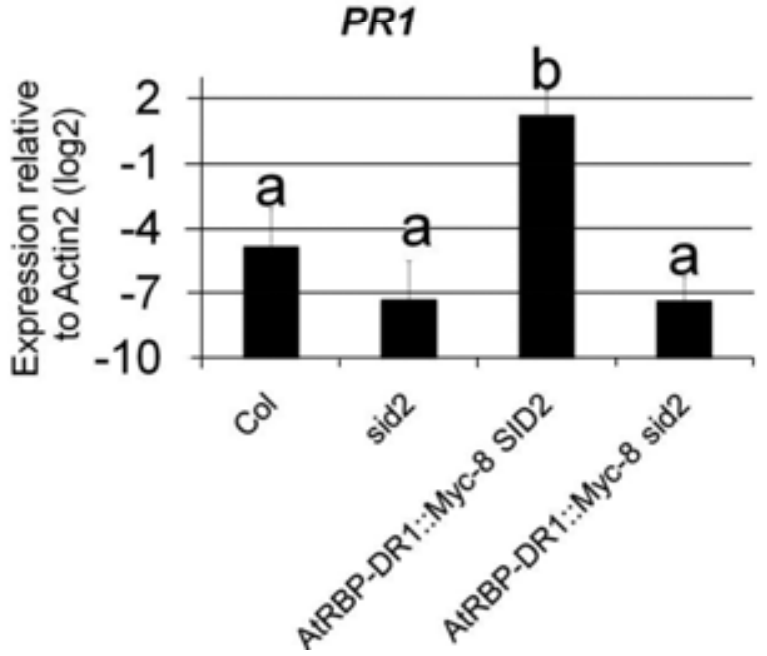

Fig. 4. AtRBP-DR1 overexpression phenotype is dependent on SID2. A, Photograph of representative rosette leaves of 6-week-old Col, sid2, AtRBP-DR1::Myc-8 SID2, and AtRBP-DR1::Myc-8 sid2. mRNA levels of B, AtRBP-DR1 and C, $P R-1$ in leaves of 6-week-old plants of the indicated genotypes were measured by quantitative reverse-transcription polymerase chain reaction. Vertical axis represents the $\log _{2}$-transformed mRNA level relative to Actin2. Data were collected from two biological replicates of $\mathrm{Col}$ and $s i d 2$ and five biological replicates of AtRBPDR1::Myc-8 SID2 and AtRBP-DR1::Myc-8 sid2. Bars represent means and standard errors calculated by a mixed linear model. Significant differences are indicated by different letters, with $P<0.05$. suggest that $A t R B P-D R l$ is involved in HR triggered by $P$. syringae pv. tomato DC3000 avrRpt2 but not by DC3000 avrRpm1 under our experimental conditions.

It was reported that SA can potentiate the HR triggered by an avirulent pathogen (Shirasu et al. 1997). Thus, the observed slower HR in the Atrbp-drl mutant and faster HR in the AtRBP-DRl overexpression line when both were challenged with $P$. syringae pv. tomato DC3000 avrRpt2 can be explained by the differences in their endogenous SA levels. Arabidopsis NahG plants express the bacterial enzyme salicylate hydroxylase and do not accumulate SA (Delaney et al. 1994). The RPS2-mediated response but not the RPM1-mediated response was greatly suppressed in NahG plants (Tao et al. 2003). In this study, we did not see differences in HR triggered by $P$. syringae pv. tomato DC3000 avrRpml in either the Atrbp-drl mutant or the AtRBP-DRI overexpression line compared with the wild type, supporting the idea that the RPM1-mediated response is less SA dependent than the RPS2-mediated response.
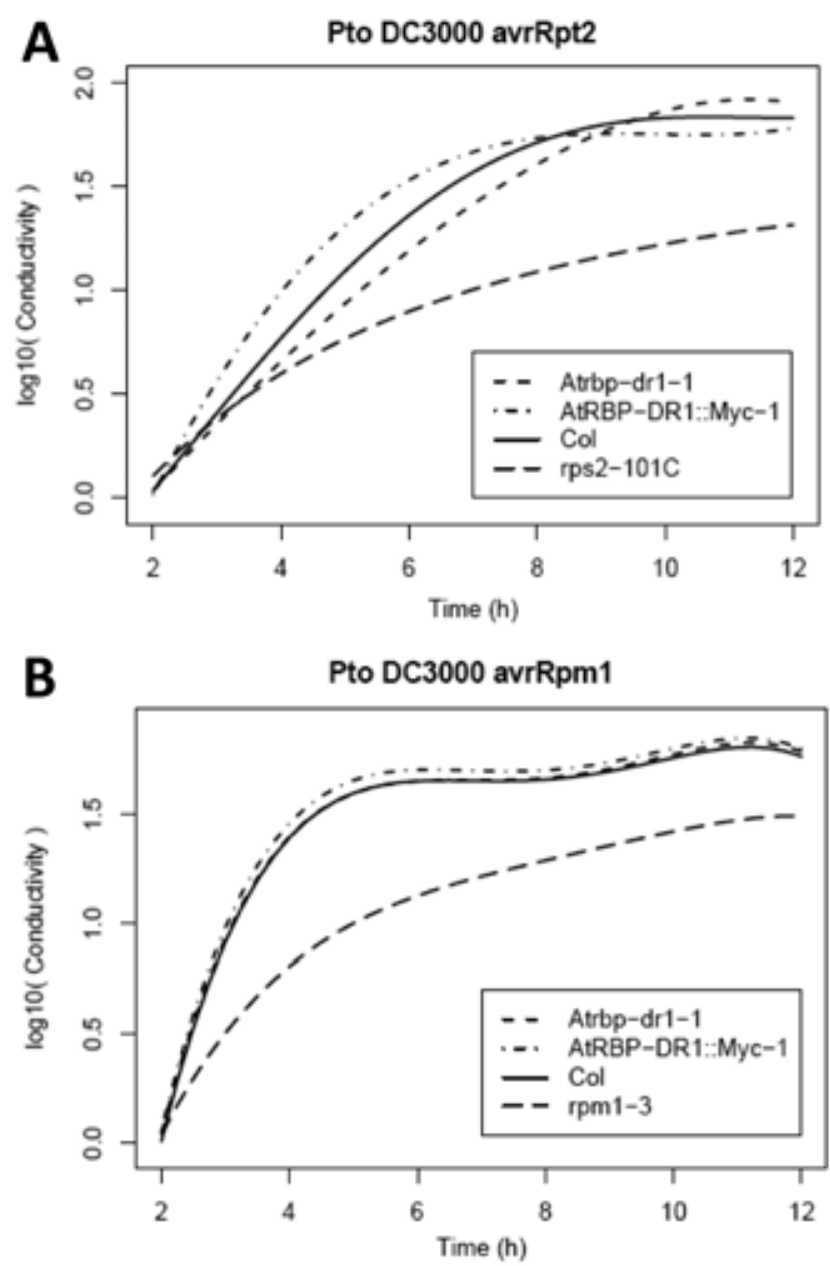

Fig. 5. AtRBP-DRl is involved in the hypersensitive response (HR) triggered by Pseudomonas syringae pv. tomato DC3000 avrRpt2. Ion leakage from leaves of 5-week-old Atrbp-dr1-1, AtRBP-DR1::Myc-1, Col, and either $\mathbf{A}, r p s 2-101 C$ or $\mathbf{B}, r p m 1-3$ after inoculation with $P$. syringae pv. tomato DC3000 A, avrRpt 2 or $\mathbf{B}$, avrRpml at a dose of $2 \times 10^{8}$ $\mathrm{CFU} / \mathrm{ml}$. Ion leakage was measured every $2 \mathrm{~h}$ from 2 to $12 \mathrm{~h}$ postinoculation (hpi) and also at 24 and $32 \mathrm{hpi}$. Data were collected in two independent experiments (with three replicates for each sample per experiment), $\log _{10}$-transformed, and analyzed with a mixed linear model after fitting a fourth-order polynomial linear model to the time course of each plant. The figure only shows the electrolyte leakage in the early time course, from 2 to $12 \mathrm{~h}$ postinoculation. 
$A t R B P-D R 1$ protein seems to be localized in the cytoplasm.

To learn more about the function of AtRBP-DR1 protein, we examined its localization in Arabidopsis rosette leaves. Confocal microscopy on multiple AtRBP-DR1::YFP::HA transgenic lines was conducted. Consistent with the overexpression phenotype described above, a stronger YFP signal was detected in smaller transgenic plants, in which the fusion protein was expressed at higher levels (Supplementary Fig. 5). AtRBPDR1::YFP::HA protein seemed to localize in the cytoplasm, particularly in the guard cells (Fig. 6A), although we cannot exclude the possibility that it also localized in the nucleus.

To confirm the cytosolic localization, lysates of AtRBP$D R 1:: M y c-8$ transgenic plants were subjected to subcellular fractionation into microsomal and soluble fractions. HSC70 isoforms were used as a soluble protein marker while RIN4 was used as a microsomal protein marker (Mackey et al. 2002). Differential detection of these proteins in the fractions indicate that the fractionation was successful (Fig. 6B). We found that AtRBP-DR1::Myc was present mainly in the soluble fraction (Fig. 6B), which confirmed the cytosolic localization of AtRBP-DR1 as found by confocal microscopy.

Some RBP can shuttle between the cytoplasm and the nucleus (Kessler et al. 1997) or reorganize within the nucleus in response to certain treatments, such as abscissic acid (Li et al. 2002; Ng et al. 2004). Therefore, we examined the possibility that AtRBP-DR1 localization may change after pathogen challenge. AtRBP-DR $1: \because Y F P:: H A-7$ transgenic plants were only slightly smaller than Col plants but the YFP signal was still detectable in this transgenic line. The leaves of the transgenic plants were inoculated with water (mock), $P$. syringae pv. tomato DC3000, or P. syringae pv. tomato DC3000 hrcC mutant. One day later, the AtRBP-DR1::YFP::HA protein localization was examined in inoculated leaves. The localization of AtRBP-DR1::YFP::HA under the three treatments was similar (Supplementary Fig. 6). Thus, AtRBP-DR1 did not appear to relocalize at the subcellular level upon $P$. syringae pv. tomato DC3000 challenge. However, we cannot exclude the possibility that AtRBP-DR1 may relocalize at other time points.

Unlike RPS2, which is a PM protein (Axtell and Staskawicz 2003). AtRBP-DR1 was found to be a cytosolic protein. AtRBP-DR1 was identified as a candidate RPS2-complex component only after application of very relaxed criteria. We have not been able to demonstrate formation of an in vivo protein complex containing both RPS 2 and AtRBP-DR1 by any other methods (not shown). Considering these facts, it is unlikely that AtRBP-DR1 and RPS2 truly form a complex.

The cytosolic localization suggests that AtRBP-DR1 may bind its RNA targets in the cytoplasm. It is conceivable that messengers of some genes affecting SA levels could be AtRBP-DR1's direct targets.

\section{$A t R B P-D R 1$ is not a substrate of HopU1 in vitro.}

An RRM motif-containing RBP, GRP7, is involved in plant defense responses against $P$. syringae pv. tomato DC3000 and localized to the cytoplasm, particularly in guard cells (Fu et al. 2007). Thus, AtRBP-DR1 and GRP7 appear to share some characteristics. Because GRP7 is ADP ribosylated by the type III effector HopU1 (Fu et al. 2007), we were curious whether HopU1 also ADP ribosylates AtRBP-DR1 to interfere with plant immunity. An in vitro assay for ADP ribosylation of GST::AtRBP-DR1 by HopU1 was conducted. GST::AtRBPDR1 was expressed in Escherichia coli, and the presence of GST::AtRBP-DR1 in the protein extract from the E. coli strain was confirmed by immunoblot using an anti-glutathione- $S$ transferase (GST) antibody (Supplementary Fig. 7A). The protein extract was then subjected to an ADP-ribosylation assay, in which ${ }^{32} \mathrm{P}$-labeled NAD was used as a substrate. If a protein is ADP ribosylated, it can be detected by autoradiography for ${ }^{32} \mathrm{P}$ signals. GST::AtRBP-DR1 did not serve as a substrate of HopU1 in this assay. Thus, AtRBP-DR1 is unlikely to be an ADP-ribosylation target of HopU1. However, $P$. syringae pv. tomato DC3000 produces at least two more effector proteins that are putative mono-ADP-ribosyltransferases: HopO1-1 and HopO1-2 (Fu et al. 2007). It remains possible that AtRBPDR1 might be a target of either or both of them.

\section{Regulation of the AtRBP-DRI mRNA level.}

Because AtRBP-DRI contributes to resistance to DC3000 strains by positively regulating the SA pathway, the extent to which pathogen infection altered AtRBP-DRI mRNA levels was examined. It has been shown that SA-related defense responses are activated in flg22-induced and $P$. syringae pv. tomato DC3000 hrcC-induced PTI (Tsuda et al. 2008). No clear change in the AtRBP-DRI mRNA level upon treatment with MAMPs (flg22 and $P$. syringae pv. tomato DC3000 hrcC) was observed at any of the three time points examined (Supplementary Fig. 8).

An effect of externally applied SA on the AtRBP-DR1 mRNA level was also tested. Liquid-cultured wild-type seed lings were treated by adding $0.5 \mathrm{mM}$ SA to the medium, and mRNA levels of AtRBP-DRI and $P R-1$ were measured by qRT-PCR $3 \mathrm{~h}$ later. Because it is SA responsive, PR-1 transcript showed a dramatic increase (more than 16-fold) $3 \mathrm{~h}$ after SA treatment (Supplementary Fig. 9). However, no significant change in the AtRBP-DRI mRNA level was observed at the same time point. Thus, AtRBPDR1's mRNA was not induced or suppressed under the tested MAMPs or SA treatment conditions.

\section{Conclusion.}

In planta, SA-mediated immunity plays a major role in the defense against biotrophic or hemibiotrophic pathogens, such as $P$. syringae pv. tomato DC3000. In this study, we demonstrated a role of the putative RNA-binding protein AtRBP-DR1 in this immunity. Our data suggest that AtRBP-DR1 positively contributes to resistance against $P$. syringae pv. tomato DC3000, through raising SA levels in a SID2-dependent manner. In the future, testing for RNA-binding activity and identification of the binding targets of AtRBP-DR1 will help us further elucidate the function of AtRBP-DR1.

\section{MATERIALS AND METHODS}

\section{Plant ecotype and mutants.}

All the plants used in this study had the genetic background of accession Col-0. Both Atrbp-drl-1 (SALK_041205) and Atrbp-drl-2 (SALK_141510) were T-DNA insertion mutants (Alonso et al. 2003). SALK_041205 was genotyped using the primers LBe, LP1, and RP1 and SALK_141510 was genotyped using primers LBe, LP2, and RP2 (Supplementary Table 1) (Sessions et al. 2002). Plant growth conditions were as described by Tsuda and associates (2008).

\section{Constructs and transgenic plants.}

The AtRBP-DRl genomic sequence containing the $1.5 \mathrm{~kb}$ upstream from the start codon was PCR amplified with the primers At4g03110-pro-5 and At4g03110-3 (without stop) from Col-0 genomic DNA, cloned into pCR8/GW/TOPO (Invitrogen, San Diego, CA, U.S.A.), and then recombined into the Gateway destination vector pEG303 (Earley et al. 2006) to obtain pEG303-pAtRBP-DR1::AtRBP-DR1::Myc. Agrobacterium tumefaciens GV3101/pMP90 was transformed with pEG303-pAtRBP-DR1-AtRBP-DR1::Myc. The transformed A. tumefaciens strain was used to transform Atrbpl-1 plants using the floral dip method (Clough and Bent 1998). T1 
transgenic plants were selected by spraying LIBERTY 200 SL herbicide (18.19\% glufosinate ammonium; Bayer Cropscience, Kansas City, MO, U.S.A.) at a 1:2,000 dilution in water. T3 homozygous plants were selected in the same manner.

The genomic sequence of the AtRBP-DRI coding sequence was PCR amplified with primers At4g03110-5 and At4g03110-3 (without stop) from Col-0 genomic DNA, cloned into pCR8/ GW/TOPO (Invitrogen), and then recombined into the Gateway destination vector pEG203, which contains the CaMV $35 \mathrm{~S}$ promoter (Earley et al. 2006), to obtain pEG203-Myc::AtRBPDR1. The remaining steps were the same as those used in generating AtRBP-DRI::Myc plants.

AtRBP-DR $1: \because Y F P:: H A$ plants were made using the same procedure as used for making $M y c:: A t R B P-D R 1$ plants, except that destination vector pEG101 (Earley et al. 2006) was used. With this construct, expression of the transgene was controlled by the CaMV $35 S$ promoter, and YFP-HA was fused to the Cterminus of the protein.

We were not successful in cloning the intron-spliced coding sequence of AtRBP-DRI directly from Arabidopsis mRNA. Instead, it was cloned in the following manner. The A. tumefaciens strain carrying pEG203-Myc::AtRBP-DR1 was suspended with MES buffer (10mM MES-KOH, $10 \mathrm{mM} \mathrm{MgCl}_{2}$, $150 \mu \mathrm{M}$ acetosyringone, $\mathrm{pH}$ 5.6) to an optical density at 600 $\mathrm{nm}\left(\mathrm{OD}_{600}\right)$ of 0.2 . The bacterial suspension was infiltrated into 4-week-old Nicotiana benthamiana leaves for transient expression. Two days later, the infiltrated leaves were collected and used for RNA extraction with TRIzol reagent (Invitrogen). The extracted RNA was then used as template for amplifying AtRBP-DR1 cDNA using RT-PCR with primers At4g03110-5 and At4g03110-3 (without stop). The amplified cDNA was cloned into $\mathrm{pCR} 8 / \mathrm{GW} / \mathrm{TOPO}$ (Invitrogen). The AtRBP-DRI cDNA was moved from the entry clone pcr8/GW/TOPO (Invitrogen) to destination vector pETDEST15 (Invitrogen) to obtain pETDEST15-GST::AtRBP-DR1.

\section{$P$. syringae strains.}

The bacterial strains $P$. syringae pv. tomato DC3000 carrying AvrRpm1 (Dangl et al. 1992), AvrRpt2 (Whalen et al.
1991), or the empty pLAFR3 vector (Staskawicz et al. 1987) were cultured in King's B medium supplemented with rifampicin $(25 \mu \mathrm{g} / \mathrm{ml})$ and tetracycline $(10 \mu \mathrm{g} / \mathrm{ml})$. The $h r c C$ mutant strain (Deng et al. 1998) was cultured in King's B medium supplemented with rifampicin $(25 \mu \mathrm{g} / \mathrm{ml})$.

\section{Bacterial growth assay.}

The $P$. syringae pv. tomato DC3000 strains were cultured at $22^{\circ} \mathrm{C}$ in King's B liquid medium supplemented with appropriate antibiotics. The overnight-cultured bacterial cells were suspended with $5 \mathrm{mM} \mathrm{MgSO}$ to a density of $2 \times 10^{5} \mathrm{CFU} / \mathrm{ml}$ $\left(\mathrm{OD}_{600}=0.0001\right)$. The bacterial suspension was infiltrated into rosette leaves of 5-week-old Arabidopsis, two leaves per plant. Two leaf discs (total surface $0.57 \mathrm{~cm}^{2}$ ) were punched from a single leaf and used as one replicate. For each genotype, six replicates were taken for day 0 and eight replicates were taken for day 2. Leaf discs were pulverized in $400 \mu \mathrm{l}$ of $5 \mathrm{mM}$ $\mathrm{MgSO}_{4}$ and a dilution series was made. For each dilution, 10 $\mu \mathrm{l}$ was streaked onto King's B plates with appropriate antibiotics and the plates were kept at $22^{\circ} \mathrm{C}$. Two days later, bacterial colonies were counted. The data collected in independent experiments were analyzed together using a mixed linear model which was described by Tsuda and associates (2008).

\section{Electrolyte leakage assay.}

The electrolyte leakage assay was conducted in a manner similar to one we described previously (Tsuda et al. 2009). Briefly, leaves of 5-week-old plants were inoculated with $P$. syringae pv. tomato DC3000 avrRpt2 or avrRpm1 at an $\mathrm{OD}_{600}$ of $0.1\left(1 \times 10^{8} \mathrm{CFU} \mathrm{m} l^{-1}\right)$. One hour after inoculation, four leaf discs were taken from two leaves of each plant and transferred to a petri dish containing $25 \mathrm{ml}$ of water. After $0.5 \mathrm{~h}$ of washing with gentle agitation, the leaf discs were transferred to glass tubes containing $6 \mathrm{ml}$ of water. The conductivity (reflecting electrolyte leakage) of the samples was determined using a portable conductivity meter (VWR Scientific, Batavia, IL, U.S.A.) at 2, 4, 6, 8, 10, 12, 24, and $32 \mathrm{~h}$ postinoculation (hpi). This experiment was repeated twice, and data from two independent experiments were combined for analysis.
A

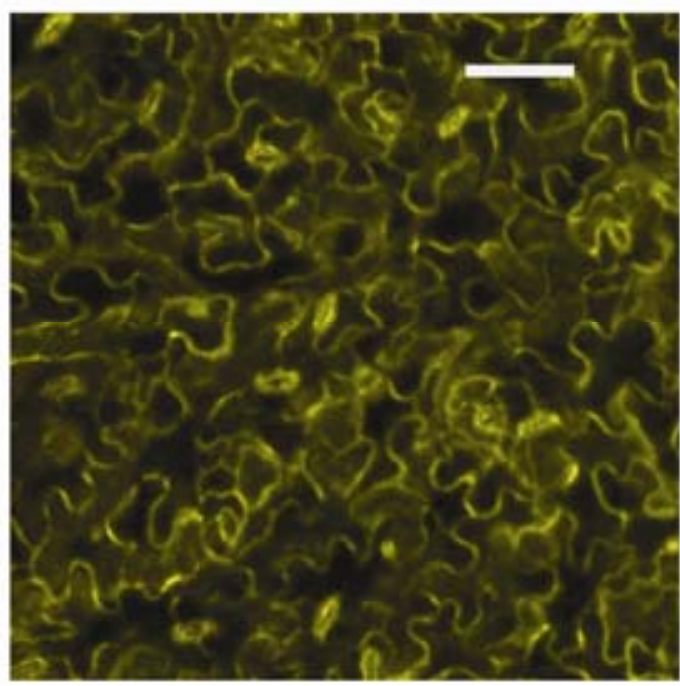

B

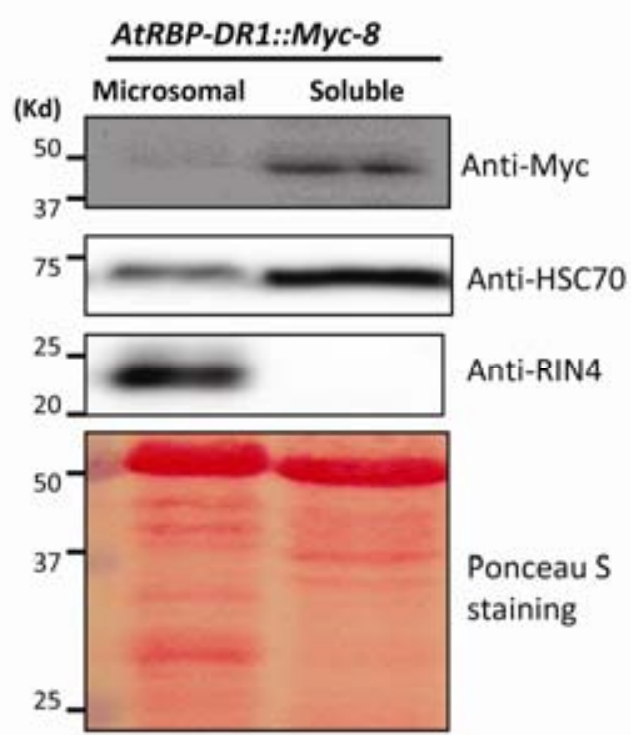

Fig. 6. AtRBP-DR1 protein appears to be cytoplasmic. A, Yellow fluorescent protein (YFP)-tagged AtRBP-DR1 was visualized in Arabidopsis epidermal cells. Rosette leaves of 6-week-old 35S:AtRBP-DR1::YFP::HA transgenic line no. 7 (T2) were visualized using confocal microscopy for YFP fluorescence. A representative picture is shown with a scale bar of $100 \mu \mathrm{m}$. B, Myc-tagged AtRBP-DR1 is a soluble protein. Total proteins were extracted from rosette leaves of 6-week-old AtRBP-DR1::Myc-8 transgenic plants and fractionated into microsomal and soluble fractions. Protein samples from both microsomal and soluble fractions were analyzed by immunoblot using anti-Myc, anti-HSC70, or anti-RIN4 antibody. Proteins transferred to a polyvinylpolypyrrolidone membrane were also visualized by Ponceau S staining. The experiment was done twice with similar results. 
Results were analyzed by fitting a polynomial linear model through the electrolyte leakage curves of individual plants and using a mixed-effect linear model on the coefficients of these curves as previously described (Van Poecke et al. 2007). Specifically, the following model was fit to the data: $C^{i j k}=S_{i}+$ $S:\left(T m+T m^{2}+T m^{3}+T m^{4}\right)_{i}+\left(1+T m+T m^{2}+T m^{3}+T m^{4}\right) \mid P_{i j}+$ $1 \mid R_{k}+\varepsilon_{i j k}$, where $C=\log _{10}$-transformed conductivity; $S=$ sample (fixed effect); $t m=$ Time (fixed effect); $P=$ plant (random effect) $R=$ replicate (random effect); $\varepsilon=$ residual; $i=1, \ldots, 8 ; j=$ $1, \ldots, 48$; and $k=1,2$. The lme function in the nlme package in the $\mathrm{R}$ environment was used. The sample was defined by the combination of the plant genotype and the bacterial strain used. The conductivity value was $\log _{10}$-transformed because the log transformation made the residual distribution close to normal. The data from 24 and 32 hpi were not included in the model fitting because the conductivity values from these late time points were highly variable. To avoid convergence problems, the coefficients of the $\left(1+T m+T m^{2}+T m^{3}+T m^{4}\right) \mid P_{i j}$ random effect were assumed to be independent, and $T m$ was centered and scaled to range from -1 to 1 .

\section{RT-PCR.}

Total RNA was extracted from 4-week-old Col, Atbrp-dr1-1, and Atrbp-dr1-2 leaves with TRIzol reagent (Invitrogen). The extracted RNA was then used as template for amplifying AtRBP-DR1 and Actin2 using a Qiagen OneStep RT-PCR kit (Qiagen, Basel, Switzerland).

\section{qRT-PCR analysis.}

For the MAMPs treatment, the RNA samples were from previous work described by Tsuda and associates (2008). Three independent experiments (biological replicates) were performed.

The following model was fit to the cycle threshold $(\mathrm{Ct})$ value data using the lme function in the nlme package in the $\mathrm{R}$ environment: $C t_{g y t r}=G Y T_{g y t}+R_{r}+\varepsilon_{g y t r}$, where $G Y T$ is a fixed effect of the gene-genotype-treatment interaction, and $R$ and $\varepsilon$ are random effects of the replicate and residual, respectively. The mean estimate of the gene-genotype-treatment interaction was used as the modeled $\mathrm{Ct}$ value. The relative $\log _{2}$ expression values were obtained by subtracting the $\mathrm{Ct}$ value of the genes from the $\mathrm{Ct}$ value of the Actin2 gene and compared for each gene using two-tailed $t$ tests. For the $t$ tests, the standard error appropriate for each comparison was calculated using the variance and covariance values obtained from the model fitting.

For the SA treatment, Col-0 seedlings were grown in liquid culture. The culture was performed as described (Denoux et al. 2008), with the following modifications: sucrose at $0.25 \mathrm{~g} /$ liter and $75 \%$ relative humidity. Ten-day-old seedlings were treated with $0.5 \mathrm{mM}$ sodium salicylate for $3 \mathrm{~h}$. Seedlings treated with water were used as a negative control. RNA extraction and quantitative RT-PCR were performed as described above.

\section{SA measurement.}

SA was analyzed by gas chromatography-mass spectrometry using deuterated SA (2-hydroxybenzoic-3,4,5,6- $\mathrm{d}_{4}$ acid; $\mathrm{C} / \mathrm{D} / \mathrm{N}$ Isotopes, Pointe-Claire, Quebec, Canada) as the internal standard, as previously described (Tsuda et al. 2008). The data were analyzed with the same mixed-effect linear model as described above ("Quantitative RT-PCR analysis").

\section{Confocal microscopy.}

Rosette leaves from 4- to 5-week-old Arabidopsis plants were cut into approximately 5-by-5-mm squares and mounted between slide and cover glasses with water. The samples were then excited with a 514-nm laser and signals were filtered through the YFP (543-nm) filter using an Eclipse C1si Spectral Imaging Confocal Microscope (Nikon, Tokyo). The images were collected using EZ-C1 software (Nikon) and further edited using Photoshop (Adobe Systems, Seattle).

\section{Trypan blue staining.}

Trypan blue staining was conducted in the same manner as we described previously (Tsuda et al. 2009).

\section{Protein sample preparation.}

For plant total protein extraction, plant leaf tissue was flashfrozen in liquid nitrogen and ground to fine powder. Then, $2 \times$ Laemmli buffer (4\% sodium dodecyl sulfate [SDS], $20 \%$ glycerol, $10 \%$ 2-mercaptoethanol, $0.004 \%$ bromphenol blue, and $0.125 \mathrm{M}$ Tris- $\mathrm{HCl}, \mathrm{pH} 6.8$ ) was added at a ratio of $1 \mathrm{~g}$ of tissue to $2 \mathrm{ml}$ of buffer. The samples were boiled for $6 \mathrm{~min}$ and centrifuged at $16,000 \times g$ for $10 \mathrm{~min}$. The supernatant was used for further analysis.

For microsomal fractionation, $1 \mathrm{~g}$ of leaf tissue from 5week-old AtRBP-DRl::Myc-8 plants was flash frozen and ground to fine powder in liquid nitrogen, followed by adding 5 $\mathrm{ml}$ of grinding buffer (50 mM HEPES-KOH [pH 7.5], $10 \mathrm{mM}$ EDTA, $330 \mathrm{mM}$ sucrose, $0.6 \%$ polyvinylpolypyrrolidone, 1 $\mathrm{mM}$ dithiothreitol, and $1 \times$ complete-mini protease inhibitor [Roche, Branchburg, NJ, U.S.A.]). The homogenate was filtered through double-layered Miracloth (Calbiochem, La Jolla, CA, U.S.A.) and the filtrate was centrifuged at $16,000 \times g$ for 15 min at $4^{\circ} \mathrm{C}$. Supernatant $(3.5 \mathrm{ml})$ was further centrifuged at $100,000 \times g$ for $1 \mathrm{~h}$ at $4^{\circ} \mathrm{C}$. The pellet was treated as the microsomal fraction and resuspended with $100 \mu \mathrm{l}$ of resuspension buffer (20 mM HEPES-KOH [pH 7.5], $1 \mathrm{mM}$ EDTA, and $330 \mathrm{mM}$ sucrose). Supernatant $(1 \mathrm{ml})$ was concentrated to 300 $\mu \mathrm{l}$ using the centrifugal filter Microcon Ultracel YM-10 (Millipore, bedford, MA, U.S.A.). Finally, an equal volume of $2 \times$ Laemmli buffer was added to both the pellet suspension and the concentrated supernatant. The samples were boiled for 6 min and centrifuged at $16,000 \times g$ for $10 \mathrm{~min}$. The supernatant was used for further analysis.

\section{Protein analysis.}

Protein samples of equal volume were separated by $10 \%$ SDS-polyacrylamide gel electrophoresis (PAGE). For immunoblot analysis, proteins resolved by SDS-PAGE were transferred from the gels to polyvinylidene difluoride membrane (Bio-Rad, Hercules, CA, U.S.A.) by semi-dry electrophoretic transfer using the TRANS-BLOT SD (Bio-Rad) device. For detection of specific proteins, the following antibodies or reagents were used: Anti-c-Myc monoclonal antibody (clone 9E10; Santa Cruz Biotechnology, Santa Cruz, CA, U.S.A.) at 1:200 dilution and goat anti-mouse HRP-conjugate (Pierce, Rockford, IL, U.S.A.); Anti-HA high-affinity monoclonal antibody (Roche, clone 3F10) at 1:500 dilution and goat anti-rat immunoglobulin G-h+I HRP conjugated (Bethyl, Montgomery, TX, U.S.A.) at 1:5000 dilution; anti-GST polyclonal antibody (no. 27-4577-01; GE Healthcare, Piscataway, NJ, U.S.A.) at 1:1,000 dilution; and rabbit anti-goat AP-conjugated (Sigma A4187). For the detection, SuperSignal West Femto Maximum Sensitivity Substrate (Pierce) was used for HRP detection and BCIP/NBT Liquid Substrate System (Sigma, St. Louis) was used for AP detection. Images were recorded using a CCD-camera. Ponceau S (Sigma) staining was used according to its manual.

\section{ADP-ribosylation assay.}

The plasmid pETDEST15-GST::AtRBP-DR1 was used to transform E. coli BL21 (DE3), and GST::AtRBP-DR1 expression was induced in the resulting transformant with $1 \mathrm{mM}$ isopropyl-thio-galactopyranoside for $3 \mathrm{~h}$. The lysates containing induced GST::AtRBP-DR1 were used for the in vitro ADPribosylation assay as described previously (Fu et al. 2007). 


\section{ACKNOWLEDGMENTS}

We thank J. Dangl of the University of North Carolina at Chapel Hill for anti-RIN4 antibody, M. Sanders and T. Anderson from the College of Biological Sciences Imaging center of University of Minnesota for technical assistance on confocal imaging, X. Sun for help with ultracentrifugation, and G. Bethke for critical reading of the manuscript. This work was supported by grant IOS-0419648 (Arabidopsis 2010 program) to J. Glazebrook and F. Katagiri, grant MCB-0918908 to F. Katagiri from the National Science Foundation, grant DE-FG02-05ER15670 from the Department of Energy Biosciences to J. Glazebrook, grant 1R01AI069146$01 \mathrm{~A} 2$ to J. R. Alfano from National Institutes of Health, and grants MCB0715951 (Arabidopsis 2010 program) and IOS-0923960 (Plant Genome Research program) to J. D. Cohen from the National Science Foundation. Y. Qi was a recipient of a Hamm Memorial Graduate Student Fellowship and a PBS Doctoral Dissertation Fellowship from the University of Minnesota. M. Sato was a recipient of a Research Fellowship of the Japan Society for the Promotion of Science for Young Scientists.

\section{LITERATURE CITED}

Alonso, J. M., Stepanova, A. N., Leisse, T. J., Kim, C. J., Chen, H., Shinn, P., Stevenson, D. K., Zimmerman, J., Barajas, P., Cheuk, R., Gadrinab, C., Heller, C., Jeske, A., Koesema, E., Meyers, C.C., Parker, H., Prednis, L., Ansari, Y., Choy, N., Deen, H., Geralt, M., Hazari, N., Hom, E., Karnes, M., Mulholland, C., Ndubaku, R., Schmidt, I., Guzman, P., Aguilar-Henonin, L., Schmid, M., Weigel, D., Carter, D. E., Marchand, T., Risseeuw, E., Brogden, D., Zeko, A., Crosby, W. L., Berry, C. C., and Ecker, J. R. 2003. Genome-wide insertional mutagenesis of Arabidopsis thaliana. Science 301:653-657.

Ausubel, F. M. 2005. Are innate immune signaling pathways in plants and animals conserved? Nat. Immunol. 6:973-979.

Axtell, M. J., and Staskawicz, B. J. 2003. Initiation of RPS2-specified disease resistance in Arabidopsis is coupled to the AvrRpt2-directed elimination of RIN4. Cell 112:369-377.

Bender, C. L., Alarcon-Chaidez, F., and Gross, D. C. 1999. Pseudomonas syringae phytotoxins: Mode of action, regulation, and biosynthesis by peptide and polyketide synthetases. Microbiol. Mol. Biol. Rev. 63:266292.

Bent, A. F., Kunkel, B. N., Dahlbeck, D., Brown, K. L., Schmidt, R., Giraudat, J., Leung, J., and Staskawicz, B. J. 1994. RPS2 of Arabidopsis thaliana: A leucine-rich repeat class of plant disease resistance genes. Science 265:1856-1860.

Cao, H., Glazebrook, J., Clarke, J. D., Volko, S., and Dong, X. 1997. The Arabidopsis NPR1 gene that controls systemic acquired resistance encodes a novel protein containing ankyrin repeats. Cell 88:57-63.

Clarke, J. D., Volko, S. M., Ledford, H., Ausubel, F. M., and Dong, X. 2000. Roles of salicylic acid, jasmonic acid, and ethylene in cpr-induced resistance in Arabidopsis. Plant Cell 12:2175-2190.

Clery, A., Blatter, M., and Allain, F. H. 2008. RNA recognition motifs: Boring? Not quite. Curr. Opin. Struct. Biol. 18:290-298.

Clough, S. J., and Bent, A. F. 1998. Floral dip: A simplified method for Agrobacterium-mediated transformation of Arabidopsis thaliana. Plant J. 16:735-743.

Clough, S. J., Fengler, K. A., Yu, I. C., Lippok, B., Smith, R. K., Jr., and Bent, A. F. 2000. The Arabidopsis dnd1 "defense, no death" gene encodes a mutated cyclic nucleotide-gated ion channel. Proc. Natl. Acad. Sci. U.S.A. 97:9323-9328.

Dangl, J. L., Ritter, C., Gibbon, M. J., Mur, L. A., Wood, J. R., Goss, S., Mansfield, J., Taylor, J. D., and Vivian, A. 1992. Functional homologs of the Arabidopsis RPM1 disease resistance gene in bean and pea. Plant Cell 4:1359-1369.

DebRoy, S., Thilmony, R., Kwack, Y. B., Nomura, K., and He, S. Y. 2004. A family of conserved bacterial effectors inhibits salicylic acid-mediated basal immunity and promotes disease necrosis in plants. Proc. Natl. Acad. Sci. U.S.A. 101:9927-9932.

Delaney, T. P., Uknes, S., Vernooij, B., Friedrich, L., Weymann, K., Negrotto, D., Gaffney, T., Gut-Rella, M., Kessmann, H., Ward, E., and Ryals, J. 1994. A central role of salicylic acid in plant disease resistance. Science 266:1247-1250.

Deng, W. L., Preston, G., Collmer, A., Chang, C. J., and Huang, H. C. 1998. Characterization of the hrpC and hrpRS operons of Pseudomonas syringae pathovars syringae, tomato, and glycinea and analysis of the ability of hrpF, hrpG, hrcC, hrpT, and hrpV mutants to elicit the hypersensitive response and disease in plants. J. Bacteriol. 180:4523-4531.

Denoux, C., Galletti, R., Mammarella, N., Gopalan, S., Werck, D., De Lorenzo, G., Ferrari, S., Ausubel, F. M., and Dewdney, J. 2008. Activation of defense response pathways by OGs and Flg22 elicitors in Arabidopsis seedlings. Mol. Plant 1:423-445.
Dinesh-Kumar, S. P., and Baker, B. J. 2000. Alternatively spliced N resistance gene transcripts: Their possible role in Tobacco mosaic virus resistance. Proc. Natl. Acad. Sci. U.S.A. 97:1908-1913.

Earley, K. W., Haag, J. R., Pontes, O., Opper, K., Juehne, T., Song, K., and Pikaard, C. S. 2006. Gateway-compatible vectors for plant functional genomics and proteomics. Plant J. 45:616-629.

Fu, Z. Q., Guo, M., Jeong, B. R., Tian, F., Elthon, T. E., Cerny, R. L., Staiger, D., and Alfano, J. R. 2007. A type III effector ADP-ribosylates RNA-binding proteins and quells plant immunity. Nature 447:284-288.

Glazebrook, J. 2005. Contrasting mechanisms of defense against biotrophic and necrotrophic pathogens. Annu. Rev. Phytopathol. 43:205-227.

Glazebrook, J., Chen, W., Estes, B., Chang, H. S., Nawrath, C., Metraux, J. P., Zhu, T., and Katagiri, F. 2003. Topology of the network integrating salicylate and jasmonate signal transduction derived from global expression phenotyping. Plant J. 34:217-228.

Gomez-Gomez, L., and Boller, T. 2000. FLS2: An LRR receptor-like kinase involved in the perception of the bacterial elicitor flagellin in Arabidopsis. Mol. Cell 5:1003-1011.

Heath, M. C. 2000. Hypersensitive response-related death. Plant Mol. Biol. 44:321-334.

Jelenska, J., Yao, N., Vinatzer, B. A., Wright, C. M., Brodsky, J. L., and Greenberg, J. T. 2007. A J domain virulence effector of Pseudomonas syringae remodels host chloroplasts and suppresses defenses. Curr. Biol. 17:499-508.

Jones, J. D., and Dangl, J. L. 2006. The plant immune system. Nature 444:323-329.

Jurkowski, G. I., Smith, R. K., Jr., Yu, I. C., Ham, J. H., Sharma, S. B., Klessig, D. F., Fengler, K. A., and Bent, A. F. 2004. Arabidopsis DND2, a second cyclic nucleotide-gated ion channel gene for which mutation causes the "defense, no death" phenotype. Mol. Plant-Microbe Interact. 17:511-520.

Kessler, M. M., Henry, M. F., Shen, E., Zhao, J., Gross, S., Silver, P. A., and Moore, C. L. 1997. Hrp1, a sequence-specific RNA-binding protein that shuttles between the nucleus and the cytoplasm, is required for mRNA 3'-end formation in yeast. Genes Dev. 11:2545-2556.

Kim, J. S., Park, S. J., Kwak, K. J., Kim, Y. O., Kim, J. Y., Song, J., Jang, B., Jung, C. H., and Kang, H. 2007. Cold shock domain proteins and glycine-rich RNA-binding proteins from Arabidopsis thaliana can promote the cold adaptation process in Escherichia coli. Nucleic Acids Res. 35:506-516.

Kim, J. S., Jung, H. J., Lee, H. J., Kim, K. A., Goh, C. H., Woo, Y., Oh, S. H., Han, Y. S., and Kang, H. 2008. Glycine-rich RNA-binding protein 7 affects abiotic stress responses by regulating stomata opening and closing in Arabidopsis thaliana. Plant J. 55:455-466.

Kim, Y. O., Kim, J. S., and Kang, H. 2005. Cold-inducible zinc finger-containing glycine-rich RNA-binding protein contributes to the enhancement of freezing tolerance in Arabidopsis thaliana. Plant J. 42:890-900.

Li, J., Kinoshita, T., Pandey, S., Ng, C. K., Gygi, S. P., Shimazaki, K., and Assmann, S. M. 2002. Modulation of an RNA-binding protein by abscisic-acid-activated protein kinase. Nature 418:793-797.

Lorkovic, Z. J. 2009. Role of plant RNA-binding proteins in development, stress response and genome organization. Trends Plant Sci. 14:229-236.

Lorkovic, Z. J., and Barta, A. 2002. Genome analysis: RNA recognition motif (RRM) and $\mathrm{K}$ homology $(\mathrm{KH})$ domain RNA-binding proteins from the flowering plant Arabidopsis thaliana. Nucleic Acids Res. 30:623-635.

Mackey, D., Holt, B. F., Wiig, A., and Dangl, J. L. 2002. RIN4 interacts with Pseudomonas syringae type III effector molecules and is required for RPM1-mediated resistance in Arabidopsis. Cell 108:743-754.

Mindrinos, M., Katagiri, F., Yu, G. L., and Ausubel, F. M. 1994. The A. thaliana disease resistance gene RPS2 encodes a protein containing a nucleotide-binding site and leucine-rich repeats. Cell 78:1089-1099.

Mou, Z., Fan, W., and Dong, X. 2003. Inducers of plant systemic acquired resistance regulate NPR1 function through redox changes. Cell 113:935-944.

Ng, C. K., Kinoshita, T., Pandey, S., Shimazaki, K., and Assmann, S. M. 2004. Abscisic acid induces rapid subnuclear reorganization in guard cells. Plant Physiol. 134:1327-1331.

Qi, Y., and Katagiri, F. 2009. Purification of low-abundance Arabidopsis plasma-membrane protein complexes and identification of candidate components. Plant J. 57:932-944.

Reddy, A. S. 2007. Alternative splicing of pre-messenger RNAs in plants in the genomic era. Annu. Rev. Plant Biol. 58:267-294.

Schenk, P. M., Kazan, K., Wilson, I., Anderson, J. P., Richmond, T., Somerville, S. C., and Manners, J. M. 2000. Coordinated plant defense responses in Arabidopsis revealed by microarray analysis. Proc. Natl. Acad. Sci. U.S.A. 97:11655-11660.

Schoning, J. C., Streitner, C., Page, D. R., Hennig, S., Uchida, K., Wolf, E., Furuya, M., and Staiger, D. 2007. Auto-regulation of the circadian slave oscillator component AtGRP7 and regulation of its targets is 
impaired by a single RNA recognition motif point mutation. Plant J. 52:1119-1130.

Sessions, A., Burke, E., Presting, G., Aux, G., McElver, J., Patton, D., Dietrich, B., Ho, P., Bacwaden, J., Ko, C., Clarke, J. D., Cotton, D., Bullis, D., Snell, J., Miguel, T., Hutchison, D., Kimmerly, B., Mitzel, T., Katagiri, F., Glazebrook, J., Law, M., and Goff, S. A. 2002. A highthroughput Arabidopsis reverse genetics system. Plant Cell 14:29852994.

Shah, J. 2003. The salicylic acid loop in plant defense. Curr. Opin. Plant Biol. 6:365-371.

Shirasu, K., Nakajima, H., Rajasekhar, V. K., Dixon, R. A., and Lamb, C. 1997. Salicylic acid potentiates an agonist-dependent gain control that amplifies pathogen signals in the activation of defense mechanisms. Plant Cell 9:261-270.

Staiger, D., Zecca, L., Wieczorek Kirk, D. A., Apel, K., and Eckstein, L. 2003. The circadian clock regulated RNA-binding protein AtGRP7 autoregulates its expression by influencing alternative splicing of its own pre-mRNA. Plant J. 33:361-371.

Staskawicz, B., Dahlbeck, D., Keen, N., and Napoli, C. 1987. Molecular characterization of cloned avirulence genes from race 0 and race 1 of Pseudomonas syringae pv. glycinea. J. Bacteriol. 169:5789-5794.

Streitner, C., Danisman, S., Wehrle, F., Schoning, J. C., Alfano, J. R., and Staiger, D. 2008. The small glycine-rich RNA binding protein AtGRP7 promotes floral transition in Arabidopsis thaliana. Plant J. 56:239-250.

Swarbreck, D., Wilks, C., Lamesch, P., Berardini, T. Z., Garcia-Hernandez, M., Foerster, H., Li, D., Meyer, T., Muller, R., Ploetz, L., Radenbaugh, A., Singh, S., Swing, V., Tissier, C., Zhang, P., and Huala, E. 2008. The Arabidopsis Information Resource (TAIR): Gene structure and function annotation. Nucleic Acids Res. 36:D1009-1014.

Tao, Y., Xie, Z., Chen, W., Glazebrook, J., Chang, H. S., Han, B., Zhu, T., Zou, G., and Katagiri, F. 2003. Quantitative nature of Arabidopsis responses during compatible and incompatible interactions with the bacterial pathogen Pseudomonas syringae. Plant Cell 15:317-330.

Thilmony, R., Underwood, W., and He, S.Y. 2006. Genome-wide transcriptional analysis of the Arabidopsis thaliana interaction with the plant pathogen Pseudomonas syringae pv. tomato DC3000 and the human pathogen Escherichia coli O157:H7. Plant J. 46:34-53.

Thines, B., Katsir, L., Melotto, M., Niu, Y., Mandaokar, A., Liu, G., Nomura, K., He, S. Y., Howe, G. A., and Browse, J. 2007. JAZ repressor proteins are targets of the $\mathrm{SCF}(\mathrm{COI} 1)$ complex during jasmonate signalling. Nature 448:661-665.
Tsuda, K., Sato, M., Glazebrook, J., Cohen, J. D., and Katagiri, F. 2008. Interplay between MAMP-triggered and SA-mediated defense responses. Plant J. 53:763-775.

Tsuda, K., Sato, M., Stoddard, T., Glazebrook, J., and Katagiri, F. 2009. Network properties of robust immunity in plants. PLoS Genet. 5:e1000772.

Uppalapati, S. R., Ayoubi, P., Weng, H., Palmer, D. A., Mitchell, R. E., Jones, W., and Bender, C. L. 2005. The phytotoxin coronatine and methyl jasmonate impact multiple phytohormone pathways in tomato. Plant J. 42:201-217.

Van Poecke, R. M. P., Sato, M., Lenarz-Wyatt, L., Weisberg, S., and Katagiri, F. 2007. Natural variation in RPS2-mediated resistance among Arabidopsis accessions: Correlation between gene expression profiles and phenotypic responses. Plant Cell 19:4046-4060.

Whalen, M. C., Innes, R. W., Bent, A. F., and Staskawicz, B. J. 1991. Identification of Pseudomonas syringae pathogens of Arabidopsis and a bacterial locus determining avirulence on both Arabidopsis and soybean. Plant Cell 3:49-59.

Wildermuth, M. C., Dewdney, J., Wu, G., and Ausubel, F. M. 2001. Isochorismate synthase is required to synthesize salicylic acid for plant defence. Nature 414:562-565.

Zhang, X. C., and Gassmann, W. 2003. RPS4-mediated disease resistance requires the combined presence of RPS4 transcripts with full-length and truncated open reading frames. Plant Cell 15:2333-2342.

Zhao, Y., Thilmony, R., Bender, C.L., Schaller, A., He, S. Y., and Howe, G. A. 2003. Virulence systems of Pseudomonas syringae pv. tomato promote bacterial speck disease in tomato by targeting the jasmonate signaling pathway. Plant J. 36:485-499.

Zipfel, C., Robatzek, S., Navarro, L., Oakeley, E. J., Jones, J. D., Felix, G., and Boller, T. 2004. Bacterial disease resistance in Arabidopsis through flagellin perception. Nature 428:764-767.

\section{AUTHOR-RECOMMENDED INTERNET RESOURCES}

Ohio State University Arabidopsis Biological Resource Center: www.abrc.osu.edu/

Salk Institute Genomic Analysis Laboratory: signal.salk.edu/cgi-bin/tdnaexpress

ExPasy Proteomics server ScanProsite website: ca.expasy.org/tools/scanprosite/ 